\title{
MENSTRUAL CYCLE IRREGULARITY AND BODY MASS INDEX AMONG SECONDARY SCHOOL STUDENTS IN SRAGEN, CENTRAL JAVA
}

\author{
Ida Untari, Tri Utami \\ School of Health (STIKES) PKU Muhammadiyah, Surakarta
}

\begin{abstract}
BACKGROUND: The Indonesian Health Survey in 2010 reported that $68.3 \%$ of women aged 10-59 years old had a regular menstrual cycle in the past one year. Approximately $13.7 \%$ of the affected women experienced problem associated with irregular menstrual cycle. Irregular menstrual cycle may cause anxiety, heighten emotional sensitivity, and disturb daily activities in the affected women. Irregular menstrual cycle occurs due to imbalanced sexual hormone. This hormonal imbalance might be worsened by poor nutritional status. This study aimed to estimate the association between irregular menstrual cycle and body mass index.

SUBJECT AND METHODS: This was a cross sectional study conducted in Sragen, Central Java. A sample of class IX secondary school (MTs) students in Kalijambe, Sragen, was selected at random for this study. The dependent variable was the menstrual cycle irregularity in the past 3 months. It was measured by a questionnaire. The independent variable was body mass index. The body weight was measured by a weight scale. The body height was measured by micro-toise. The association between study variables was estimated by Spearman correlation coefficient.

RESULTS: Fifty percent of the sample had normal body weight, $43.8 \%$ were underweight, $6.3 \%$ were obese. As much as $12.5 \%$ of them had irregular menstrual cycle. There was a very weak and statistically nonsignificant correlation between body mass index and menstrual cycle irregularity ( $\mathrm{r}=0.08 ; \mathrm{p}=0.183)$.

CONCLUSION: There was a very weak and statistically non-significant correlation between body mass index and menstrual cycle regularity.
\end{abstract}

Keywords: menstrual cycle, regularity, body mass index 